\title{
Alternative pathways for hydrogen sink originated from the ruminal fermentation of carbohydrates: Which microorganisms are involved in lowering methane emission?
}

\author{
Ana Margarida Pereira* ${ }^{*}$, Maria de Lurdes Nunes Enes Dapkevicius and Alfredo E. S. Borba
}

\begin{abstract}
Agriculture is responsible for a great share of the anthropogenic sources of greenhouse gases that, by warming the earth, threaten its biodiversity. Among greenhouse gas emissions, enteric $\mathrm{CH}_{4}$ from livestock is an important target to slow down climate changes. The $\mathrm{CH}_{4}$ is originated from rumen fermentation and its concentration is affected by several factors, including genetics and nutrition. Ruminants have an extraordinary symbiosis with microorganisms (bacteria, fungi, and protozoa) that ferment otherwise indigestible carbohydrates, from which they obtain energy to grow and continue actively producing, among other products, volatile fatty acids, $\mathrm{CO}_{2}$ and $\mathrm{H}_{2}$. Detrimental ruminal accumulation of $\mathrm{H}_{2}$ is avoided by methanogenesis carried out by Archaea methanogens. Importantly, methanogenesis is not the only $\mathrm{H}_{2}$ sink pathway. In fact, other bacteria can reduce substrates using metabolic hydrogen formed during carbohydrate fermentation, namely propionate production and reductive acetogenesis, thus lowering the $\mathrm{CH}_{4}$ produced. Although the complexity of rumen poses challenges to mitigate $\mathrm{CH}_{4}$ production, the emergence of sequencing techniques that allow the study of microbial communities, gene expression, and metabolome are largely contributing to unravel pathways and key players in the rumen. Indeed, it is now recognized that in vivo emissions of $\mathrm{CH}_{4}$ are correlated to microbial communities, and particularly with the abundance of methanogens, several bacterial groups, and their genes. The goal of $\mathrm{CH}_{4}$ mitigation is to work in favor of the natural processes, without compromising rumen function, animal health, and productivity. Notwithstanding, the major challenge continues to be the feasibility and affordability of the proposed solutions.
\end{abstract}

Keywords: Acetogenesis, $\mathrm{H}_{2}$ sink, Methanogenesis, Microorganisms, Propionate, Rumen fermentation

\section{Introduction}

Global warming threatens biodiversity alongside the life of humans. Among other gases, the release of $\mathrm{CO}_{2}$ and $\mathrm{CH}_{4}$ into the atmosphere contributes significantly to the greenhouse effect, a phenomenon that prevents the reflection of solar energy back from the earth's surface,

\footnotetext{
*Correspondence: ana.mb.pereira@uac.pt

Faculdade de Ciências Agrárias e do Ambiente, Instituto de Investigação em Tecnologias Agrárias e do Ambiente (IITAA), Universidade dos Açores, Campus de Angra do Heroísmo, rua Capitão João d'Ávila, 9700-042,

Açores, Angra do Heroísmo, Portugal
}

causing a rise in temperature [1]. Agriculture is responsible for a great share of the anthropogenic sources of greenhouse gases (GHG) [1]. According to FAO (2013), GHG emission from livestock represents $14 \%$ of humaninduced emissions, being beef and dairy cattle the main contributors [2]. Within the livestock sector, feed production, processing, and transportation account for $\approx$ $45 \%$ of total GHG, followed by enteric $\mathrm{CH}_{4}$ emissions $(\approx$ 40\%) [2]. Therefore, acting over this latter source constitutes an opportunity to achieve the goals of the Green 
Deal, which seeks for a 55\% cut in GHG emission by 2030, compared to 1990 levels [3].

Although animal farming is often cited as the cause of the problem, it can actually be part of the solution. If other anthropogenic activities (e.g., burning of fossil fuels) slow down the emission of $\mathrm{CO}_{2}$, mitigation of GHG emission, or at least the share from the livestock sector, might be achieved by sequestration of carbon in grasslands [4]. Carbon from the atmosphere $\left(\mathrm{CO}_{2}\right)$ is fixed in the soil mainly through plant photosynthesis and thus converted into organic material (e.g., grasses and forages), which is then consumed by grazing animals [5]. From the ruminal fermentation of carbohydrates, $\mathrm{CH}_{4}$ is produced at the expense of energy and released into the atmosphere, where after approximately 10 years, it is broken down and converted back into $\mathrm{CO}_{2}$, giving continuity to the natural carbon cycling, in a process called the biogenic carbon cycle (Fig. 1) [6]. Therefore, in theory, the reduction of animal production, which entails a decrease in protein availability, is not the only alternative to tackle GHG emission. Instead, enhancing animal productivity while decreasing $\mathrm{CH}_{4}$ might be a sustainable option, not compromising feed for a growing population. In the latest years, a lot of effort has been put into the study of animal breeding [7], vaccines [8], dietary management, and additives [9], as means to mitigate $\mathrm{CH}_{4}$ emissions. Despite positive results reported in some studies, there is still not a consensus at a global scale, mainly because the efficacy and feasibility of each proposed strategy are affected by several factors. Such include the farming system, acceptability of both consumers and farmers, policies, and financial support [10].

As the majority of $\mathrm{CH}_{4}$ is produced in the rumen, strategies for mitigating $\mathrm{CH}_{4}$ emissions, necessarily affect the rumen microbiome and vice-versa. The rumen is harbored by a consortium of microorganisms including protozoa, bacteria, archaea, and fungi that conjointly enable the fermentation of otherwise indigestible carbohydrates such as cellulose and hemicellulose into volatile fatty acids (VFA; e.g., acetate, propionate, and butyrate). Other products of carbohydrate fermentation include formate, ethanol, lactate, succinate, branched-chain volatile fatty acids, ammonia, $\mathrm{CO}_{2}$, and $\mathrm{H}_{2}$ [11]. Dissolved $\mathrm{H}_{2}$ and $\mathrm{CO}_{2}$ are utilized by methanogens, a group of microorganisms belonging to the Archaea domain, to form $\mathrm{CH}_{4}$. Despite being the main pathway to avoid the accumulation of $\mathrm{H}_{2}$ in the rumen, methanogenesis constitutes a loss of energy, reflected in animal productivity (e.g., methane emission has been correlated to residual feed intake [12]) and is strongly affected by diet (e.g., the level of concentrate has been correlated to $\mathrm{CH}_{4}$ yield in grazing cows $[13,14])$. However, methanogenesis is not the only $\mathrm{H}_{2}$ sink mechanism in the rumen [15], being alternative pathways worth exploring. Therefore, the present work aims to summarize mitigation of $\mathrm{CH}_{4}$ production, via alternative $\mathrm{H}_{2}$ disposal pathways, namely, propionate production and reductive acetogenesis.

\section{Microbial composition of the rumen}

The rumen is a foregut ecosystem that hosts an enormous number of microbes living in symbiosis with the host. It is estimated to harbor a concentration of archaea of $10^{7}$ to $10^{9}$ cells $/ \mathrm{ml}$, bacteria of $10^{10}$ to $10^{11}$ cells $/ \mathrm{ml}$, protozoa of $10^{4}$ to $10^{6}$ cells $/ \mathrm{ml}$, and fungi of $10^{3}$ to $10^{6}$ cells $/ \mathrm{ml} \mathrm{[16].}$ Putting these into perspective, the number of ruminal microbial cells of an adult dairy cow (estimated volume of 50 to $200 \mathrm{~L}$ ) [17] is 40 to 500 times the number of human

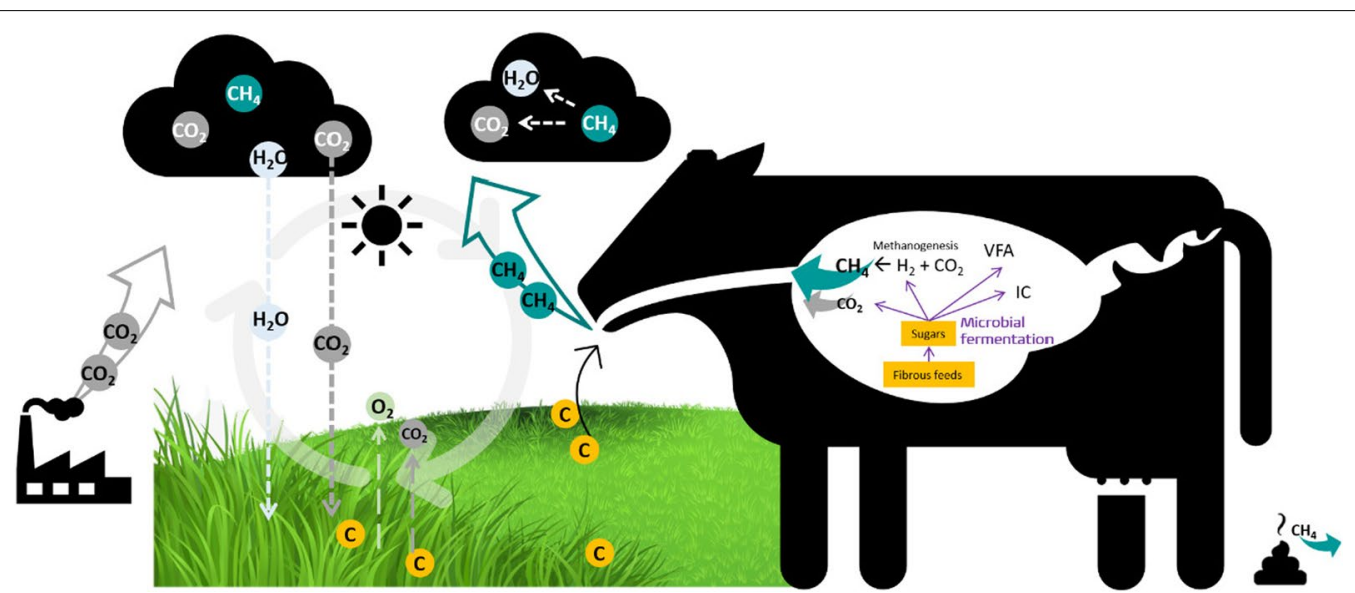

Fig. 1 Simplified scheme of rumen methane production and emission and the biogenic carbon cycle. C designates carbon, fixated in plants from $\mathrm{CO}_{2}$ through photosynthesis, which is then consumed by animals as carbohydrates. VFA, volatile fatty acids; IC, intermediary compounds and/or other products 
cells constituting an adult body (assuming the estimation of $3.72 \times 10^{13}$ total cells by Bianconi et al. [18]).

\section{Archaea}

Archaea in the rumen consist of methanogens belonging to the phylum Euryarcheota [19]. It is represented by four orders Methanobacteriales, Methanococcales, Methanomicrobiales, and Methanosarcinales [20]. Methanobacteriales include the genera Methanobacterium and the dominant genus Methanobrevibacter, which is divided into two clades, (1) clade Methanobrevibacter gottschalki that also includes the species Mbb. thaueri and Mbb. millerae; and (2) clade Methanobrevibacter ruminantium that also includes Mbb. olleyae [21]. Most methanogens use $\mathrm{H}_{2}$ for the reduction of $\mathrm{CO}_{2}$ into $\mathrm{CH}_{4}$ [22], although formate might also be used instead of $\mathrm{CO}_{2}$ by Methanobrevibacter, some strains of Methanobacterium spp., and Methanomicrobiales, such as genus Methanomicrobium [20]. In addition, methanogens of order Methanococcales and Methanosarcinales can utilize methyl groups (e.g., genus Methanosphaera also uses methanol, whereas genera Methanosarcina and Methanimicrococcus also use methylamines), and acetate (e.g., Methanosarcina) to produce $\mathrm{CH}_{4}$ [20]. Methanol is originated from the demethyoxylation of dietary pectins, whereas mono-, di-, and tri-methylamines are mainly end-products of plant phosphatidylcholine degradation [23]. The structure of the methanogenic community at the species or strain level has been correlated with feed efficiency [24]. Moreover, some authors argue that feed efficiency is related to $\mathrm{CH}_{4}$ emissions [12, 25], although the link between both is complex and influenced by multiple parameters related to the rumen microbiome [26] and host factors (e.g., passage rate and nutrient absorption) [27]. Importantly, dominant archaea groups were found similar in samples collected from ruminants across the globe, which is likely an advantage to develop and implement worldwide strategies to mitigate $\mathrm{CH}_{4}$ emissions targeting methanogens [19].

\section{Bacteria}

The rumen harbors cellulolytic and non-cellulolytic bacteria, being the first able to degrade cellulose and hemicelluloses. Primary cellulose fermenters are Fibrobacter succinogenes, Ruminococcus flavefaciens, and Ruminococcus albus. These bacteria are non-motile, adhering extensively to the fibers through the glycocalyx, and having cellulases located on the cell surface [28]. They hydrolyze cellulose and other polysaccharides (e.g., hemicelluloses and pectin), producing cellodextrins to utilize as a source of energy and make available for cross-feeding [28]. This is important to provide nutrients for the growth of other bacteria and/or non-adherent cells of the same species that are poised to adhesion to new feed particles [29]. Secondary cellulose fermenters, including Butyrivibrio fibrisolvens, Clostridiurn longisporum, and Clostridium locheadii, might be motile or non-motile, adhering minimally to fibers, and having extracellular cellulases [28]. Non-cellulolytic bacteria, able to degrade starch, hemicelluloses, or pectin, might include Prevotella ruminantium, Eubacterium xylanophilum, Ruminobacter amylophilus, Succinimonas amylolytica, Succinivibrio dextrinosolvens, Selenomonas ruminantium, Selenomonas lactilytica, Lachnospira multiparus, Streptococcus bovis, and Megasphaera elsdenii [30].

Despite the great diversity of bacterial species in the rumen, an extensive study reported the existence of 30 most abundant bacterial groups comprising $\approx 89 \%$ of total sequences found on livestock species [19]. Among them, Prevotella, Butyrivibrio, and Ruminococcus, unclassified Lachnospiraceae, Ruminococcaceae, Bacteroidales, and Clostridiales were predominant, having an abundance of $\approx 67 \%$. Later works analyzing metagenome-assembled genomes (MAGs) revealed the existence of new genomes from the Actinobacteria, Fibrobacteres, and Proteobacteria phyla, also highlighting the abundance of genus Succinivibrio [31].

The existence of a core ruminal bacterial microbiome has been suggested, despite a clear variation associated with host and diet [19]. Indeed, a study reported that the breed is more determinant for metabolites and bacterial communities of bovines than diet and life-stage [32]. Even though the age and time of weaning significantly affect the diversity and abundance of rumen microbial communities [33], it has been suggested that colonization of rumen starts in utero, as samples collected in goat fetuses allowed the identification of sequences mainly belonging to the phylum Proteobacteria [34]. Also, three moments were shown to produce important shifts in rumen bacteria: delivery, milk intake, and weaning [34]. Moreover, it was reported that the rumen microbial colonization is affected differently by natural or artificial milk feeding systems [35], and the inoculation of young ruminants with fresh rumen fluid from adult animals enhanced microbial colonization, likely improving rumen development [36]. Furthermore, early life modulation of the rumen microbiome has been a matter of study regarding its effectiveness when compared to later interventions for the improvement of rumen fermentation and reduction of $\mathrm{CH}_{4}$ emission [37].

\section{Protozoa}

Contrary to archaea and bacteria, ciliate protozoa vary across ruminants of different species as well as individuals of the same species [19]. A study in cattle indicated that Entodinium, Diplodinium, Eremoplastron, 
Ostracodinium, Eodinium, Epidinium, Isotricha, and Dasytricha were among the most abundant genera $(>1 \%)$ of a total of 13 identified in the ruminal fluid by microscopic identification and counting [38]. Conversely, in sheep and goats, 12 and 8 genera were identified, being Dasytricha, Entodinium, Eudiplodinum, Diplodinium, Isotricha, and Metadinium the more abundant (>1\%) in both species, and Enoploplastron, Ophryoscolex, and Polyplastron only in sheep [39].

Protozoa attach to the surface of partially digested feed particles, in which other microorganisms exert high fibrolytic activity, allowing them to take advantage of monosaccharides (e.g., glucose, cellobiose, and cellodextrins) that they use as their source of energy for growth and metabolism [40]. Also, protozoa predate bacteria from which they obtain amino acids for growth and maintenance [41]. Non-surprisingly, ciliate protozoa affect the diversity of ruminal bacteria [42] and end-fermentation products. However, protozoa are not essential for ruminal fermentation and removal of protozoa from the rumen, also called defaunation, does not seem to significantly impact animal health, although feed digestibility might be affected [41]. The potential of defaunation to mitigate $\mathrm{CH}_{4}$ emission has been studied $[43,44]$. The external surface of protozoa is a site for methanogen attachment (ectosymbionts) or intracellular colonization (endosymbionts), which are attracted by the $\mathrm{H}_{2}$ produced in protozoan hydrogenosomes [41]. This symbiosis enhances methanogenesis and favors protozoa as it reduces the levels of $\mathrm{H}_{2}$, enabling them to continue the fermentation of monosaccharides left by bacteria. Indeed, the protozoan-associated methanogens are estimated to be responsible for $37 \%$ of $\mathrm{CH}_{4}$ emission [45], and a meta-analysis including several in vivo studies concluded that a reduction of protozoa concentration was, in most cases, associated with a reduction of $\mathrm{CH}_{4}$ emission [46]. Nevertheless, as noted by some authors, defaunation has implications on other metabolic pathways (e.g., fatty acids), which likely justifies a holistic view of the use of this strategy for $\mathrm{CH}_{4}$ mitigation [47]. Ionophore additives were suggested for reduction of $\mathrm{CH}_{4}$ emission, due to their positive [48] and transient effects [49] on reduction of protozoans and methanogens. However, environmental contamination with still active antibiotics is detrimental for the environment and needs to be considered [50]. Other strategies targeting rumen protozoans include the supplementation of plant metabolites, such as essential oils, which disrupt protozoal membrane, indirectly reducing methanogens [51-53].

\section{Fungi}

More than $90 \%$ of fungi sequences isolated in the rumen remain unclassified [54], however, the presence of anaerobic fungi belonging to phylum Neocallimastigomycetes (genera Neocallimastix, Caecomyces, Piromyces, Anaeromyces, Orpinomyces, and Cyllamyces) is acknowledged [55]. Fungi are infrequently found in strained rumen fluid because zoospores attach and colonize (encyst and germinate to produce the fungal thallus) the plant fragments suspended in the rumen natural digesta, being only then released by the sporangia [56]. This may have contributed to a greater unawareness of the importance of their fibrolytic activity. Nonetheless, fungi have enzymes to degrade plant cell wall carbohydrates [55] and are indeed more efficient in degrading lignin than bacteria [57]. In co-culture with methanogens, Neocallimastix exhibited high lignocellulose-degrading activity with the production of $\mathrm{CH}_{4}$ and acetate [58]. Other studies support the importance of fungi as substrate and electron donors for methanogenesis [59], which makes fungal metabolic pathways an attractive subject for study in the context of the mitigation of $\mathrm{CH}_{4}$ emission.

\section{Ruminal carbohydrate digestion}

Plant cell wall polysaccharides are arrangements of glycosidic linkages (e.g., mono-, di-, and oligosaccharides) and noncarbohydrate moieties [60], and might be analytically grouped into cellulose, hemicellulose, and pectin [30]. Cellulose, the most abundant component of cell wall plants, is formed by $\beta$-glucose and other hexoses. Whereas, hemicellulose, mainly composed of pentoses with linear xylose chains and variable linkages of arabinose, uronic acids, and galactose, is the second most abundant [61]. Pectin is present in the primary cell wall and has D-galacturonate in its structure [30]. Moreover, starch, a non-structural carbohydrate, is composed of $\alpha$-glucose, constituting the major carbohydrate storage in plants and an important source of energy for ruminants [62]. Ruminal microorganisms cleave complex glycosidic bonds mainly through glycoside hydrolases. Indeed, the enrichment in those enzymes observed in Bacteroidales, including Prevotellaceae, Fibrobacteres, and some Clostridiales [63], affords them a competitive advantage justifying its higher abundance in the rumen.

Chewing and rumination are important for carbohydrate digestion carried out by ruminal microorganisms, as it facilitates the adhesion of bacteria to plants, hydrating and disrupting the protective cuticular layer of plants [29]. After specific adhesion, in which bacterial-substrate linkages and adhesins are developed, the proliferation and colonization of plant tissues are initiated [29]. This is possible because the fermentation of sugars leads to the formation of ATP, the main source of energy for microorganisms [61]. Microbial enzymes degrade the hexoses primarily through the Embden-Meyerhof pathway, originating $\mathrm{NADH}$ and pyruvate. Hemicellulose 
has two pathways for degradation, the transketolase and transaldolase reactions of the pentose cycle or phosphoketolase, with the products originated entering the Embden-Meyerhof pathway [61]. Continuation of the metabolism of the intermediate compound pyruvate is dependent on the oxidation of cofactors (e.g., NADH) through pathways that lead to the formation of lactate, succinate, acetate, propionate, butyrate, ethanol, and valerate [64]. The several reactions that occur in rumen fermentation entail the formation and incorporation of metabolic hydrogen $[\mathrm{H}]$. Formation corresponds to the transfer of electron donors of metabolic intermediates to oxidized intracellular cofactors (highlighted in pink in Fig. 2). Conversely, incorporation corresponds to the transfer from reduced intracellular cofactors to metabolic intermediate electron acceptors (highlighted in green in Fig. 2) [65]. This electron transfer is carried out by hydrogenases and originates $\mathrm{H}_{2}$. Furthermore, $\mathrm{H}_{2}$ and $\mathrm{CO}_{2}$ might also be originated from the conversion of formate in the pyruvate-ferredoxin oxidoreductase [64]. Hydrogen is then transferred between producing species (bacteria, protozoa, and fungi) and hydrogenotrophic microorganisms, mainly methanogens.

\section{Methanogenesis and $\mathrm{CH}_{4}$ emission}

Rumen methanogenesis is known to occur by three different pathways: hydrogenotrophic (A), acetoclastic (B), and methylotrophic (C) [20]:

$$
\begin{aligned}
& \text { (A) } 4 \mathrm{H}_{2}+\mathrm{CO}_{2} \rightarrow \mathrm{CH}_{4}+2 \mathrm{H}_{2} \mathrm{O} \\
& 4 \mathrm{HCOOH} \rightarrow \mathrm{CH}_{4}+3 \mathrm{CO}_{2}+2 \mathrm{H}_{2} \mathrm{O} \\
& \text { (B) } \mathrm{CH}_{3} \mathrm{COOH} \rightarrow \mathrm{CH}_{4}+\mathrm{CO}_{2} \\
& \text { (C) } 4 \mathrm{CH}_{3} \mathrm{OH} \rightarrow 3 \mathrm{CH}_{4}+\mathrm{CO}_{2}+2 \mathrm{H}_{2} \mathrm{O} \\
& 4 \mathrm{CH}_{3}-\mathrm{NH}_{2}+2 \mathrm{H}_{2} \mathrm{O} \rightarrow 3 \mathrm{CH}_{4}+\mathrm{CO}_{2}+4 \mathrm{NH}_{3} \\
& 2\left(\mathrm{CH}_{3}\right)_{2}-\mathrm{NH}+2 \mathrm{H}_{2} \mathrm{O} \rightarrow 3 \mathrm{CH}_{4}+\mathrm{CO}_{2}+2 \mathrm{NH}_{3} \\
& 4\left(\mathrm{CH}_{3}\right)_{3}-\mathrm{N}+6 \mathrm{H}_{2} \mathrm{O} \rightarrow 9 \mathrm{CH}_{4}+3 \mathrm{CO}_{2}+4 \mathrm{NH}_{3}
\end{aligned}
$$

Hydrogenotrophic methanogenesis is largely the most frequent, which likely occurs because the energetics involved is more favorable, resulting in slower growth rates and lower cell yields for microorganisms involved in the other methanogenesis pathways [22]. The genus Methanobrevibacter, a highly abundant hydrogenotroph, has been correlated with high $\mathrm{CH}_{4}$ emissions in steers [66], heifers [67], and dairy cows (more particularly $M b b$. gottschalkii and Mbb. ruminantium) [68]. In turn, Methanosphaera (methylotroph) was negatively correlated with $\mathrm{CH}_{4}$ emission in heifers [67] and dairy cows [69, 70]. This might be explained by the stoichiometric of the reaction, as one mole of $\mathrm{CO}_{2}$ is required to produce one mole of $\mathrm{CH}_{4}$ (A), while four moles of methanol are required to produce three moles of $\mathrm{CH}_{4}$ (B) in the methylotrophic pathway [69]. Interestingly, the methylotrophic pathway appears to be more significant in young calves compared to mature cows [71]. Even though methylotrophs might have a lower $\mathrm{CH}_{4}$ yield, they release $\mathrm{NH}_{3}$ to add to the amount already produced by proteolytic bacteria [72] Importantly, methyl-coenzyme $M$ reductase, which catalyzes the final step of methanogenesis is common across the different methanogenesis pathways [73], which is likely an advantage for strategies intending to target directly methanogens. An example is 3-nitrooxypropanol, a molecule that was shown to inhibit methanogenesis by oxidizing the active site $\mathrm{Ni}(\mathrm{I})$ of methyl-coenzyme $M$ reductase [74].

Despite the differences reported in microbial abundances, metagenomic and metatranscriptomic sequencing studies showed that the increased expression of methanogenesis pathway genes explains the increase in $\mathrm{CH}_{4}$ emissions, which might itself be regulated by a substrate effect [75]. The diversity of methanogens in the rumen has been correlated to $\mathrm{CH}_{4}$ emission. A study using co-abundance analysis of rumen microorganisms of cows reported that low- $\mathrm{CH}_{4}$ emitting animals had a more diverse community of methanogens involved in the three methanogenic pathways, compared with high- $\mathrm{CH}_{4}$ emitting ones, which had low numbers of hydrogenotrophic methanogenic genera [76]. This shows that methanogen diversity is correlated to $\mathrm{CH}_{4}$ emission and highlights the interaction between communities and competition among methanogens for $\mathrm{H}_{2}$. Also, low- $\mathrm{CH}_{4}$ cow emitters exhibited a more complex microbial network composed of a diverse microbiome, more specifically, bacterial and fungal genera and their genes [76]. Indeed, differences in the microbiome of low- and high- $\mathrm{CH}_{4}$ emitters are not limited to methanogens, which is not surprising as the availability of precursors for methanogenesis is dictated by the fermentative microbial consortium. Experimentally, $S$. dextrinosolvens in co-culture enhanced a member of Methanomassiliicoccales and inhibited the activity of a member of the Mbb. gottschalkii clade [77]. An in vivo study showed that low- $\mathrm{CH}_{4}$ emitting sheep were associated with an elevated abundance of L-lactate dehydrogenase genes, an enrichment of genus Sharpea (family Erysipelotrichiacaea), and decreased abundance of families Lachnospiraceae and Ruminococcaceae [78]. These results were confirmed by another study using MAG on microbial sequences collected in high and low $\mathrm{CH}_{4}$ emitting sheep, allowing the identification of differential abundance of other genera and microorganisms at the species level [31]. Low- $\mathrm{CH}_{4}$ emitting sheep had, in addition to previously mentioned, a high abundance of Kandleria, Fibrobacter, and Selenomonas at a genus level, whereas at a species level, Fibrobacter succinogenes and several species of Bifidobacterium, Olsenella, Desulfobrivio were more abundant [31], compared to high emitting sheep. In dairy cows, the abundance of genera 


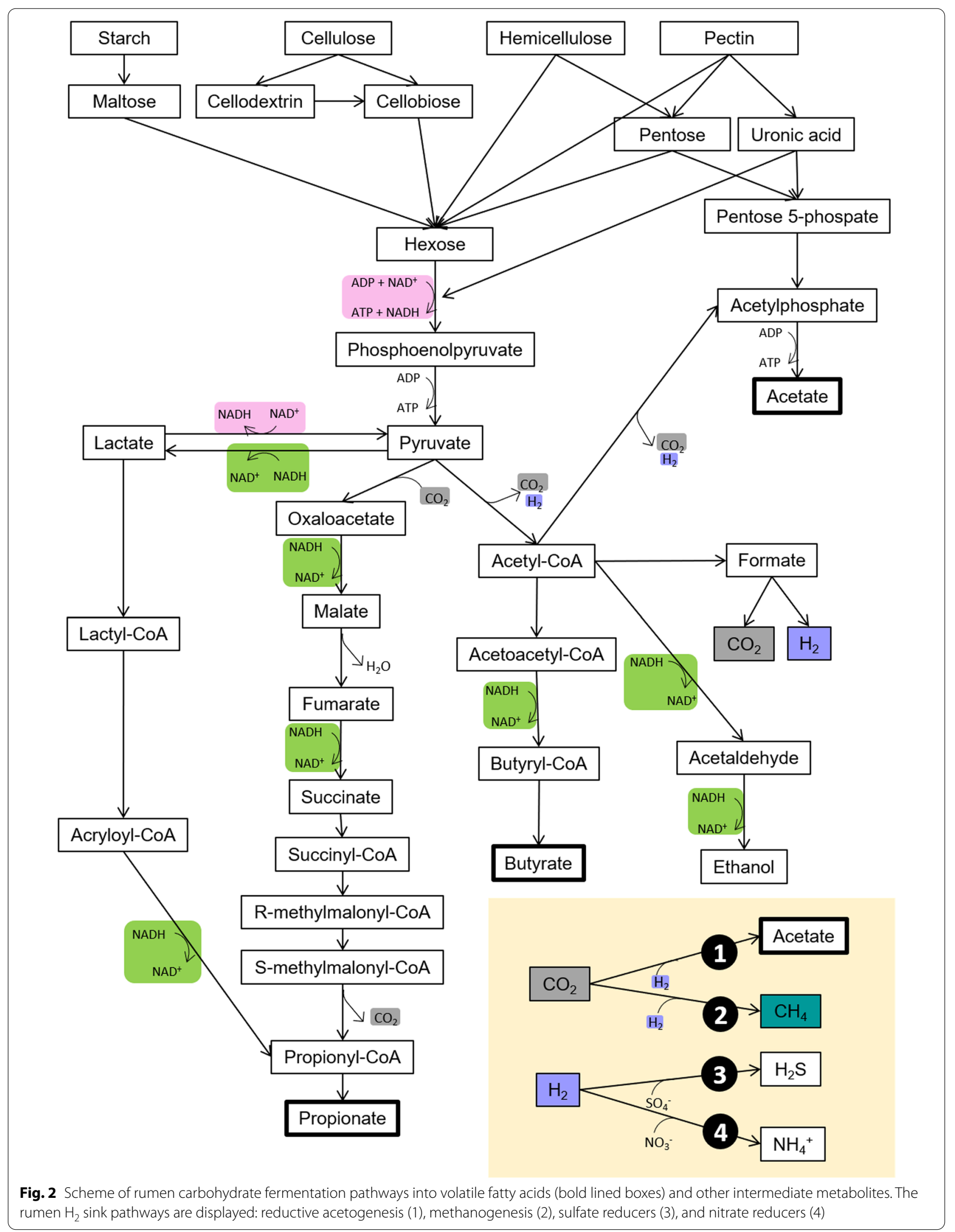


Christensenellaceae, Mogibacteriaceae, S24-7, Butyrivibrio, Shwartzia, and Treponema was associated with low $\mathrm{CH}_{4}$ emission in one study [69] and with genus Eubacterium in another, in which rumen samples of heifers were analyzed [67]. It is important to consider that effects of the host (e.g., ruminant species), diet as well as methodologies (e.g., sequencing technique and/or 16S rRNA hypervariable region selected) might preclude a direct comparison of microbial composition across studies.

Age and physiological states affect the rumen microbiome composition and thus $\mathrm{CH}_{4}$ yields, as shown in a study in heifers, in which the interaction of genera Prevotella and Methanobrevibacter was associated with the $\mathrm{CH}_{4}$ yield, while in older cows, the significant interaction was between Methanobrevibacter and Succinivibrio [79]. Interestingly though, a study reported that early and late lactation stages were correlated with different levels of $\mathrm{CH}_{4}$ emissions not accompanied by changes in the rumen microbiome [80]. In a study with Colombian buffalos, the genus Prevotella was associated with low $\mathrm{CH}_{4}$ emissions [81]. Despite the differences reported in archaea composition between buffalo and cattle [82], this bacterial group seems relevant for $\mathrm{CH}_{4}$ emission of both species. As some authors pointed, the host genotype affects the phenotype of $\mathrm{CH}_{4}$ emission, in addition to its microbial community [81]. Indeed, one study indicated that $\mathrm{H}_{2}$-producing bacteria explained up to $24 \%$ of $\mathrm{CH}_{4}$ phenotypic variance, and host genome, 14\% [70]. In another study, the $\mathrm{CH}_{4}$ emission had a cumulative effect of archaea and bacteria of $13 \%$ and $21 \%$ of host genetics [83]. Despite the percentage difference, both studies suggest that targeting the rumen microbiome of low- $\mathrm{CH}_{4}$ emitting animals (through breeding programs) is possible and likely more effective than not considering the host genome and heritability of the trait.

\section{Alternative pathways to $\mathrm{H}_{\mathbf{2}}$ sink}

As previously stressed, the concentration of $\mathrm{H}_{2}$ determines the $\mathrm{CH}_{4}$ produced, while the production of $\mathrm{H}_{2}$ is determined by the prevailing pathways of glucose fermentation. The fermentation into butyrate (D) and acetate $(E)$ entails a potential production of one mole of $\mathrm{H}_{2}$ (per mole of glucose), whereas propionate (F) entails a net incorporation of one mole of $\mathrm{H}_{2}$ (per mole of glucose) [65]. This balance considers the reducing equivalents $[2 \mathrm{H}]$ produced and incorporated through several reactions (Fig. 2). Microbial cells able to change their fermentation patterns and better adapt to certain conditions are likely more active degrading the available substrates, thus managing to expand [84]. The concentration of $\mathrm{H}_{2}$ conditions the fermentation pathway, affecting the free energy change between reactants and products in which the microbial biomass thrives. Summarily, high concentrations of $\mathrm{H}_{2}$ favor the productions of propionate, whereas low concentrations of $\mathrm{H}_{2}$ favors the production of acetate [11]:

(D) $\mathrm{C}_{6} \mathrm{H}_{12} \mathrm{O}_{6} \rightarrow 2 \mathrm{CH}_{3} \mathrm{CH}_{2} \mathrm{CH}_{2} \mathrm{COO}^{-}+\mathrm{CO}_{2}+2 \mathrm{H}_{2}+\mathrm{H}^{+}$

(E) $\mathrm{C}_{6} \mathrm{H}_{12} \mathrm{O}_{6}+2 \mathrm{H}_{2} \mathrm{O} \rightarrow 2 \mathrm{CH}_{3} \mathrm{COO}^{-}+2 \mathrm{CO}_{2}+2 \mathrm{H}^{+}+4 \mathrm{H}_{2}$

(F) $\mathrm{C}_{6} \mathrm{H}_{12} \mathrm{O}_{6} \rightarrow \mathrm{CH}_{3} \mathrm{CH}_{2} \mathrm{COO}^{-}+2 \mathrm{H}_{2} \mathrm{O}+2 \mathrm{H}^{+}$

A recent study analyzing MAGs of the microbiota of gastrointestinal ruminants reported that $48 \%$ encoded enzymes for fermentative $\mathrm{H}_{2}$ production, $1.5 \%$ for $\mathrm{H}_{2}$-uptake hydrogenases and the methyl-coenzyme $\mathrm{M}$ reductase (mcrA genes) related to hydrogenotrophic methanogenesis, while $11 \%$ encoded both hydrogenases and the required terminal reductases of alternative methanogenesis pathways. Acetogenesis constituted $3 \%$ of MAGs, fumarate $1.9 \%$, and sulfate reduction $0.8 \%$ [26]. It has been proposed that the microbial hydrogenases and fermentation pathways are differentially regulated through direct $\mathrm{H}_{2}$ sensing by putative sensory [FeFe]-hydrogenases [15]. Indeed, sensory hydrogenases, as well as fermentative and bifurcating hydrogenases, are highly expressed in Clostridiales, Bacteroidales, and Selenomonadales, whereas methanogenic hydrogenases are present, by order of expression, in Methanobacteriales $>$ Methanomassiliicoccales $>$ Methanosarcinales [15]. Moreover, low- $\mathrm{CH}_{4}$ emitting sheep were reported to have higher hydrogenase and terminal reductase transcripts from alternative $\mathrm{H}_{2}$ uptake pathways, which might even serve as a larger $\mathrm{H}_{2}$ sink than methanogenesis, compared to high- $\mathrm{CH}_{4}$ emitters [15]. This highlights the preponderant role of the bacterial consortium in determining $\mathrm{H}_{2}$ metabolism and the strategies of methanogens to compete and affect $\mathrm{H}_{2}$ utilization, and thus $\mathrm{CH}_{4}$ emission.

Dietary manipulation of $\mathrm{H}_{2}$ production has been attempted to reduce $\mathrm{CH}_{4}$ emissions, and it is highly associated with changes in ruminal microbiota. Higher concentrations of $\mathrm{H}_{2}$ are associated with high starch content diets, likely because $\mathrm{H}_{2}$ release outgrows the capacity of $\mathrm{H}_{2}$-consuming microorganisms, leading to an accumulation [85]. Hydrogen accumulation was also associated with diets containing tannin-rich peanut skin provided to beef cattle due to the reduction of $\mathrm{H}_{2}$-using microorganisms, including populations of Bacteroidetes phylum, total methanogens, Methanobrevibacter, and protozoa, concomitantly reducing methanogenesis [84]. Supplementation of non-fermentative sources, such as $\mathrm{Mg}$, was shown to increase ruminal dissolved $\mathrm{H}_{2}$, which affected the microbiota, decreasing the copy number of fungi in goats [86].

In addition to diet effects, host factors and $\mathrm{H}_{2}$-producing microorganisms interact, conditioning $\mathrm{H}_{2}$ production. Indeed, a study in sheep reported that 
animals with a smaller rumen volume emitted proportionally less $\mathrm{CH}_{4}$, presumably because their higher feed rate passage selected microorganisms able to grow on soluble sugars that can be quickly degraded [78], thus increasing $\mathrm{H}_{2}$.

Directly targeting methanogens and potentiating other $\mathrm{H}_{2}$-using microorganisms (e.g., propionate pathway, reductive acetogenesis, nitrate, and sulfate reduction) have been proposed as strategies to mitigate $\mathrm{CH}_{4}$ emissions. Sulfate-reducing bacteria (e.g., nitrate-reducing propionibacteria, Wolinella succinogenes, and Veillenolla parvula) can reduce nitrate and nitrocompounds into $\mathrm{N}_{2} \mathrm{O}$ and $\mathrm{NH}_{4}$ [87], and although studies [88] have proven it effective in decreasing methanogenesis, concerns over toxicity have hindered its use and motivated further research to develop safer additives (e.g., encapsulated nitrite [89]). Sulfate-reducing bacteria (e.g., Desulfovibrio) reduce sulfate into $\mathrm{H}_{2} \mathrm{~S}$, competing with methanogens for $\mathrm{H}_{2}$ and reducing methanogenesis if ruminal levels of sulfate increase [90]. Despite thermodynamics and matrix affinity favors sulfate reduction over methanogenesis, as seen in marine sediments [90, 91], the product is highly toxic to the animal.

\section{Propionate pathway}

Ruminal propionate originates mainly from succinate and acrylate pathways. The fermentation of carbohydraterich diets with high levels of soluble sugars promotes the proliferation of amylolytic microorganisms such as $S$. bovis [92], Lactobacillus, and Bifidobacterium [93] that reduce pyruvate into lactate. In physiological conditions (no acidosis), microorganisms such as M. elsdenii and Coprococcus catus produce propionate from lactate via the acrylyl-CoA, using the acrylate pathway [94]. Indeed, both $M$. elsdenii and C. catus were correlated to higher feed efficiency and lower $\mathrm{CH}_{4}$ emissions in dairy cows [95].

The production of propionate from lactate can also occur with a first oxidation to pyruvate, followed by carboxylation to oxaloacetate, reduction to malate, dehydration to fumarate, reduction to succinate, and a final decarboxylation to propionate (Fig. 2) [96]. This, also called the 'randomizing' pathway, might be carried out by microorganisms such as S. ruminantium [97] and Succiniclasticum ruminis (unable to ferment substrates other than succinate) [98]. According to an in vitro study, the addition of fumarate-reducing bacteria, Mitsuokella jalaludinii, lowered methanogen DNA copies and occurrence through competition for $\mathrm{H}_{2}$ [99]. Similarly, supplementation with enterococci (E. faecalis and E. faecium) exhibited fumarate reductase activity, with an increase of propionate and a decrease of $\mathrm{CH}_{4}$ [100]. Another in vitro study reported the potential effects of propionic bacteria on ruminal feed degradation by showing a reduction of $\mathrm{CH}_{4}$ from 8 to $20 \%$ associated with one strain of Propionibacterium jensenii and two of Propionibacterium thoenin [101]. Lactiplantibacillus plantarum was also shown to decrease in vitro $\mathrm{CH}_{4}$ production and increased propionate [102]. In turn, an in vivo study showed that, when provided for 4 weeks to lactating primiparous cows fed contrasting high-starch or high-fiber diets, Propionibacterium freudenreichii, Lactiplantibacillus pentosus, and Lactobacillus delbrueckii subsp. bulgaricus did not affect $\mathrm{CH}_{4}$ emissions [103]. This highlights the need to further study the in vivo effects of lactic acid bacteria to elucidate any potential correlation with the in vitro positive results. The use of lactic acid bacteria requires finding delivery options that have already been implemented in the global farming system (e.g., silage inoculants and direct-fed microbes), a challenge that must be addressed [104].

Manipulation of fiber content, namely by the replacement of forage fiber by non-forage fiber sources, promoted an expansion of Firmicutes over Bacteroidetes and of Methanobrevibacter over Methanomassiliicoccus, and a successful shift of $\mathrm{H}_{2}$ flow towards the propionate pathway [105]. Furthermore, feed supplementation with saponin (which causes cell rupture and lysis of protozoan) was shown to shift fermentation products, lowering butyrate and increasing propionate [106].

In vivo studies associated other bacteria such as genera Succinivibrio (family Succinivibrionaceae), Roseburia, and Blautia (family Lachnospiraceae) with the increase of propionate, when testing diets that differed in the corn processing techniques [107]. Furthermore, family Succinivibrionaceae were effectively associated with high propionate and low $\mathrm{CH}_{4}$ yield [66, 108].

Adding to its potential as a methanogenesis competitor, the increase of propionate production is advantageous for cows' health and efficiency. The major share $(50-75 \%)$ of propionate produced is absorbed into the portal vein [109]. Propionate is the main precursor of hepatic gluconeogenesis and essential to supply glucose to the mammary gland, thus contributing to support milk production [110]. Furthermore, infusions of propionate led to greater plasma progesterone concentrations post-ovulation, which can affect follicular development and pregnancy rates, and thus improve reproductive efficiency [111].

\section{Reductive acetogenesis}

Acetogenesis has been documented as an alternative to methanogenesis, in which via the acetyl-CoA pathway, two moles of $\mathrm{CO}_{2}$ and four moles of $\mathrm{H}_{2}$ are incorporated per one mole of acetate produced (G), in a thermodynamically feasible set of reactions. 


$$
4 \mathrm{H}_{2}+2 \mathrm{CO}_{2} \rightarrow \mathrm{CH}_{3} \mathrm{COOH}+2 \mathrm{H}_{2} \mathrm{O} .
$$

Acetogens degrade multiple substrates (e.g., pentoses, hexoses, alcohols, formate, and methyl groups) in addition to $\mathrm{H}_{2}$, and in the rumen of cows and sheep, the dominant microorganisms are members of Lachnospiraceae, Clostridiaceae, and Ruminococcaceae families [112, 113]. The threshold value for $\mathrm{H}_{2}$ utilization is lower for methanogens than it is for acetogens, which renders reductive acetogenesis a disadvantage. Therefore, increasing $\mathrm{H}_{2}$ pressure would remove methanogenesis thermodynamic advantage [114]. An in vitro study reported that supplementation of acetogen Eubacterium limosum was able to produce acetate when methanogens were suppressed concomitantly, but a minimal change in $\mathrm{CH}_{4}$ production was observed when methanogenesis was not inhibited [115]. Similarly, in vitro supplementation with E. limosum and Proteiniphilum acetatigenes decreased $\mathrm{CH}_{4}$ concentrations, increased acetate, whereas in vivo, $P$. acetatigenes was associated with high milk protein, lower somatic cell counts, and lower decline of milk production over 60 days [116].

\section{Conclusions}

Several in vivo studies employing sequencing techniques have revealed distinct ruminal microbial communities between high- and low- $\mathrm{CH}_{4}$ emitting animals. That knowledge has recently been prompted by metagenomics and transcriptomics that allow not only studying the rumen microbial composition but also its function, unraveling genes and pathways involved in the metabolism of $\mathrm{H}_{2}$. The goal of successful interventions is likely shifting $\mathrm{H}_{2}$ from methanogenesis, exploiting natural processes, without compromising rumen physiology. That depends upon the interaction between microbial communities, including several orders of bacteria, archaea, and eukaryotes that encode and express enzymes [15], thus mediating ruminal fermentation pathways. The propionate pathway competes with methanogenesis, improving efficiency. Using additives including probiotics to promote propionate production showed good results in vitro, yet in vivo studies are still required to confirm its efficacy as well as its suitability for widespread use. Dietary management, namely the use of concentrates and high rich-carbohydrate diets that naturally select microorganisms involved in the propionate pathway make this a more suitable strategy for intensive production systems. However, the carbon footprint of diet production and transportation must be placed in the equation. Reductive acetogenesis is suitable for grazing animals, in which degradation of fibrous diets originates $\mathrm{H}_{2}$ that can be utilized by acetogens, though a combined strategy to reduce methanogens is required.
Even though knowledge on the ruminal microbiome has expanded, there are still several genes and microorganisms whose characterization and function remains unknown, particularly protozoan and fungi. Recent works have recovered archaeal and bacterial MAGs from metagenomic data, from which new, previously unnoticed, pathways and networks have been discovered. This indicates that the ruminal microbiome study is a work in progress and may provide us new prospects for finding solutions for lowering livestock enteric $\mathrm{CH}_{4}$ emissions, thus addressing the role of cattle in the current climate emergency.

\section{Abbreviations \\ GHG: Greenhouse gases; MAGs: Metagenome-assembled genomes; VFA: Volatile fatty acids.}

\section{Acknowledgements}

Not applicable.

\section{Authors' contributions}

AESB, AMP, and MLNED conceived the work; AMP conducted the investigations and drafted the manuscript; AESB, AMP, and MLNED revised the manuscript. All authors read and approved the final manuscript.

\section{Funding}

The authors acknowledge the financial support of the Portuguese Foundation for Science and Technology (FCT; UIDB/00153/2020). A.M.P. acknowledges FCT for the individual funding (UIDP/00153/2020).

\section{Availability of supporting data}

Not applicable.

\section{Declarations}

Ethics approval and consent to participate Not applicable.

Consent for publication

Not applicable.

\section{Competing interests}

The authors declare no competing interests.

Received: 5 August 2021 Accepted: 17 December 2021

Published online: 06 January 2022

\footnotetext{
References

1. Moss AR, Jouany J-P, Newbold J. Methane production by ruminants: its contribution to global warming. Ann Zootech. 2000;49:231-53. https:// doi.org/10.1051/animres:2000119.

2. Gerber PJ, Steinfeld H, Henderson B, Mottet A, Opio C, Dijkman J, et al. Tackling climate change through livestock — a global assessment of emissions and mitigation opportunities. Rome: Food and Agriculture Organization of the United Nations (FAO); 2013.

3. European Commission Secretariat-General. Communication from the commission to the european parliament, the european council, the council, the european economic and social committee and the committee of the regions - The European Green Deal COM/2019/640 final. 2019. https://eur-lex.europa.eu/legal-content/EN/ALL/?uri=COM:2019: 640:FIN.

4. Soussana JF, Tallec T, Blanfort V. Mitigating the greenhouse gas balance of ruminant production systems through carbon sequestration in
} 
grasslands. Animal. 2010;4:334-50. https://doi.org/10.1017/S175173110 9990784.

5. Gougoulias C, Clark JM, Shaw LJ. The role of soil microbes in the global carbon cycle: tracking the below-ground microbial processing of plant-derived carbon for manipulating carbon dynamics in agricultural systems. J Sci Food Agric. 2014;94:2362-71.

6. Raiten DJ, Allen LH, Slavin JL, Mitloehner FM, Thoma GJ, Haggerty PA, et al. Understanding the intersection of climate/environmental change, health, agriculture, and improved nutrition: a case study on micronutrient nutrition and animal source foods. Curr Dev Nutr. 2020;4:1-8.

7. González-Recio O, López-Paredes J, Ouatahar L, Charfeddine N, Ugarte E, Alenda R, et al. Mitigation of greenhouse gases in dairy cattle via genetic selection: 2 . Incorporating methane emissions into the breeding goal. J Dairy Sci. 2020;103:7210-21. https://doi.org/10.3168/jds. 2019-17598.

8. Baca-González V, Asensio-Calavia P, González-Acosta S, de la Lastra JMP, de la Nuez AM. Are vaccines the solution for methane emissions from ruminants? A systematic review. Vaccines. 2020;8:1-21.

9. Haque MN. Dietary manipulation: a sustainable way to mitigate methane emissions from ruminants. J Anim Sci Technol. 2018:60:15. https:// doi.org/10.1186/s40781-018-0175-7.

10. Key $\mathrm{N}$, Tallard G. Mitigating methane emissions from livestock: a global analysis of sectoral policies. Clim Change. 2012;112:387-414. https:// doi.org/10.1007/s10584-011-0206-6.

11. Janssen PH. Influence of hydrogen on rumen methane formation and fermentation balances through microbial growth kinetics and fermentation thermodynamics. Anim Feed Sci Technol. 2010;160:1-22.

12. Fitzsimons C, Kenny DA, Deighton MH, Fahey AG, McGee M. Methane emissions, body composition, and rumen fermentation traits of beef heifers differing in residual feed intake1. J Anim Sci. 2013;91:5789-800. https://doi.org/10.2527/jas.2013-6956.

13. Jiao HP, Dale AJ, Carson AF, Murray S, Gordon AW, Ferris CP. Effect of concentrate feed level on methane emissions from grazing dairy cows. J Dairy Sci. 2014;97:7043-53. https://doi.org/10.3168/jds.2014-7979.

14. van Wyngaard JDV, Meeske R, Erasmus LJ. Effect of concentrate level on enteric methane emissions, production performance, and rumen fermentation of Jersey cows grazing kikuyu-dominant pasture during summer. J Dairy Sci. 2018;101:9954-66. https://doi.org/10.3168/jds. 2017-14327.

15. Greening C, Geier R, Wang C, Woods LC, Morales SE, McDonald MJ, et al. Diverse hydrogen production and consumption pathways influence methane production in ruminants. ISME J. 2019:13:2617-32.

16. Wright $A D G$, Klieve AV. Does the complexity of the rumen microbial ecology preclude methane mitigation? Anim Feed Sci Technol. 2011;166-167:248-53.

17. Membrive CMB. Anatomy and physiology of the Rumen. In: Millen DD, De Beni AM, Lauritano Pacheco RD, editors. Rumenology. 1st ed. Cham: Springer International Publishing; 2016. p. 1-38. https://doi.org/10. 1007/978-3-319-30533-2_1.

18. Bianconi E, Piovesan A, Facchin F, Beraudi A, Casadei R, Frabetti F, et al. An estimation of the number of cells in the human body. Ann Hum Biol. 2013;40:463-71. https://doi.org/10.3109/03014460.2013.807878.

19. Henderson G, Cox F, Ganesh S, Jonker A, Young W, Janssen PH, et al. Rumen microbial community composition varies with diet and host, but a core microbiome is found across a wide geographical range. Sci Rep. 2015; . https://doi.org/10.1038/srep14567.

20. Liu Y, Whitman WB. Metabolic, phylogenetic, and ecological diversity of the methanogenic archaea. Ann N Y Acad Sci. 2008;1125:171-89.

21. Janssen PH, Kirs M. Structure of the archaeal community of the rumen. Appl Environ Microbiol. 2008;74:3619-25.

22. Fenchel T, King GM, Blackburn TH. Bacterial Metabolism. In: Fenchel T, King GM, Blackburn THBT, editors. Bacterial biogeochemistry. 3rd ed. Boston: Academic Press; 2012. p. 1-34. https://doi.org/10.1016/ B978-0-12-415836-8.00001-3.

23. Kelly WJ, Leahy SC, Kamke J, Soni P, Koike S, Mackie R, et al. Occurrence and expression of genes encoding methyl-compound production in rumen bacteria. Anim Microbiome. 2019;1:1-13.

24. Zhou M, Hernandez-Sanabria E, Guan LL. Characterization of variation in rumen methanogenic communities under different dietary and host feed efficiency conditions, as determined by
PCR-Denaturing Gradient Gel Electrophoresis analysis. Appl Environ Microbiol. 2010;76:3776-86. https://doi.org/10.1128/AEM.00010-10.

25. Sakamoto LS, Souza LL, Gianvecchio SB, de Oliveira MHV, Silva JV, Canesin RC, et al. Phenotypic association among performance, feed efficiency and methane emission traits in Nellore cattle. PLoS ONE. 2021;16:e0257964. https://doi.org/10.1371/journal.pone.0257964.

26. Xie F, Jin W, Si H, Yuan Y, Tao Y, Liu J, et al. An integrated gene catalog and over 10,000 metagenome-assembled genomes from the gastrointestinal microbiome of ruminants. Microbiome. 2021;9:137. https:// doi.org/10.1186/s40168-021-01078-x.

27. Dijkstra J, Kebreab E, Mills JAN, Pellikaan WF, López S, Bannink A, et al. Predicting the profile of nutrients available for absorption: from nutrient requirement to animal response and environmental impact. Animal. 2007;1:99-111. https://doi.org/10.1017/S1751731107657760.

28. Weimer PJ. Why don't ruminal bacteria digest cellulose faster? J Dairy Sci. 1996;79:1496-502. https://doi.org/10.3168/jds.S0022-0302(96) 76509-8.

29. Miron J, Ben-Ghedalia D, Morrison M. Invited review: adhesion mechanisms of rumen cellulolytic bacteria. J Dairy Sci. 2001;84:1294-309. https://doi.org/10.3168/jds.S0022-0302(01)70159-2.

30. Wang Y, McAllister TA. Rumen microbes, enzymes and feed digestionA Review. Asian-Australas J Anim Sci. 2002;15:1659-76. https://doi. org/10.5713/ajas.2002.1659.

31. Stewart RD, Auffret MD, Warr A, Walker AW, Roehe R, Watson M. Compendium of 4,941 rumen metagenome-assembled genomes for rumen microbiome biology and enzyme discovery. Nat Biotechnol. 2019:37:953-61. https://doi.org/10.1038/s41587-019-0202-3.

32. Lee HJ, Jung JY, Oh YK, Lee S-S, Madsen EL, Jeon CO. Comparative survey of rumen microbial communities and metabolites across one caprine and three bovine groups, using bar-coded pyrosequencing and ${ }^{1} \mathrm{H}$ nuclear magnetic resonance spectroscopy. Appl Environ Microbiol. 2012;78:5983-93. https://doi.org/10.1128/AEM.00104-12.

33. Amin N, Schwarzkopf S, Kinoshita A, Tröscher-Mußotter J, Dänicke S, Camarinha-Silva A, et al. Evolution of rumen and oral microbiota in calves is influenced by age and time of weaning. Anim Microbiome. 2021;3:31. https://doi.org/10.1186/s42523-021-00095-3.

34. Zou X, Liu G, Meng F, Hong L, Li Y, Lian Z, et al. Exploring the rumen and cecum microbial community from Fetus to adulthood in goat. Animals. 2020;10:1639.

35. Ramos-Morales E, Pinloche E, Denman SE, Newbold CJ, Yáñez-Ruiz DR. Natural and artificial feeding management before weaning promote different rumen microbial colonization but not differences in gene expression levels at the rumen epithelium of newborn goats. PLOS ONE. 2017:12:1-19.

36. Palma-Hidalgo JM, Jiménez E, Popova M, Morgavi DP, Martín-García $\mathrm{Al}$, Yáñez-Ruiz DR, et al. Inoculation with rumen fluid in early life accelerates the rumen microbial development and favours the weaning process in goats. Anim Microbiome. 2021. https://doi.org/10. 1186/s42523-021-00073-9.

37. Yáñez-Ruiz DR, Abecia L, Newbold CJ. Manipulating rumen microbiome and fermentation through interventions during early life: a review. Front Microbiol. 2015. https://doi.org/10.3389/fmicb.2015. 01133.

38. Rossi MF, Martinele I, D'Agosto M. Quantitative and differential analysis of ciliate protozoa in rumen content samples filtered before and after fixation. Rev Bras Zootec. 2013;42:831-4.

39. Gürelli G, Canbulat S, Aldayarov N, Dehority BA. Rumen ciliate protozoa of domestic sheep (Ovis aries) and goat (Capra aegagrus hircus) in Kyrgyzstan. FEMS Microbiol Lett. 2016;363:1-7.

40. Leng RA. Interactions between microbial consortia in biofilms: a paradigm shift in rumen microbial ecology and enteric methane mitigation. Anim Prod Sci. 2014;54:519-43.

41. Newbold CJ, de la Fuente G, Belanche A, Ramos-Morales E, McEwan NR. The role of ciliate protozoa in the rumen. Front Microbiol. 2015;6:1313. https://doi.org/10.3389/fmicb.2015.01313.

42. Ozutsumi Y, Tajima K, Takenaka A, Itabashi H. The effect of protozoa on the composition of rumen bacteria in cattle using 16S rRNA gene clone libraries. Biosci Biotechnol Biochem. 2005;69:499-506.

43. Nguyen SH, Nguyen HDT, Bremner G, Hegarty RS. Methane emissions and productivity of defaunated and refaunated sheep while grazing. 
Small Rumin Res. 2018;161:28-33. https://doi.org/10.1016/j.smallrumres.2018.02.004.

44. Belanche A, De La Fuente G, Newbold CJ. Effect of progressive inoculation of fauna-free sheep with holotrich protozoa and total-fauna on rumen fermentation, microbial diversity and methane emissions. FEMS Microbiol Ecol. 2015. https://doi.org/10.1093/femsec/fiu026.

45. Finlay BJ, Esteban G, Clarke KJ, Williams AG, Embley TM, Hirt RP. Some rumen ciliates have endosymbiotic methanogens. FEMS Microbiol Lett. 1994;117:157-61. https://doi.org/10.1111/j.1574-6968.1994.tb06758.x.

46. Guyader J, Eugène M, Nozière P, Morgavi DP, Doreau M, Martin C. Influence of rumen protozoa on methane emission in ruminants: a meta-analysis approach. Animal. 2014;8:1816-25.

47. Francisco AE, Santos-Silva JM, Portugal APV, Alves SP, Bessa RJB. Relationship between rumen ciliate protozoa and biohydrogenation fatty acid profile in rumen and meat of lambs. PLOS ONE. 2019;14:1-21.

48. Guan H, Wittenberg KM, Ominski KH, Krause DO. Efficacy of ionophores in cattle diets for mitigation of enteric methane1. J Anim Sci. 2006;84:1896-906. https://doi.org/10.2527/jas.2005-652.

49. Crossland WL, Tedeschi LO, Callaway TR, Miller MD, Smith WB, Cravey M. Effects of rotating antibiotic and ionophore feed additives on volatile fatty acid production, potential for methane production, and microbial populations of steers consuming a moderate-forage diet. J Anim Sci. 2017;95:4554-67. https://doi.org/10.2527/jas2017.1665.

50. Takahashi J, Iwasa M. Entomological approach to the impact of ionophore-feed additives on greenhouse gas emissions from pasture land in cattle. J Anim Sci Technol. 2021;63:16-24. https://doi.org/10. 5187/jast.2021.e11.

51. Ku-Vera JC, Jiménez-Ocampo R, Valencia-Salazar SS, Montoya-Flores MD, Molina-Botero IC, Arango J, et al. Role of secondary plant metabolites on enteric methane mitigation in ruminants. Front Vet Sci. 2020. https://doi.org/10.3389/fvets.2020.00584/full.

52. Durmic Z, Moate PJ, Eckard R, Revell DK, Williams R, Vercoe PE. In vitro screening of selected feed additives, plant essential oils and plant extracts for rumen methane mitigation. J Sci Food Agric. 2014;94:11916. https://doi.org/10.1002/jsfa.6396.

53. Khorrami B, Vakili AR, Mesgaran MD, Klevenhusen F. Thyme and cinnamon essential oils: potential alternatives for monensin as a rumen modifier in beef production systems. Anim Feed Sci Technol. 2015;200:8-16. https://doi.org/10.1016/j.anifeedsci.2014.11.009.

54. Wang H, Li P, Liu X, Zhang C, Lu Q, Xi D, et al. The composition of fungal communities in the rumen of Gayals (Bos frontalis), Yaks (Bos grunniens), and Yunnan and Tibetan Yellow Cattle (Bos taurs). Pol J Microbiol. 2019;68:505-14. https://doi.org/10.33073/pjm-2019-050.

55. Puniya AK, Singh R, Kamra DN (editors). Rumen fungi. In: Rumen microbiology: from evolution to revolution. 2015. p. 1-379. https://doi.org/ 10.1007/978-81-322-2401-3_7.

56. Bauchop T. Rumen anaerobic fungi of cattle and sheep. Appl Environ Microbiol. 1979;38:148-58.

57. Janusz G, Pawlik A, Sulej J, Świderska-Burek U, Jarosz-Wilkołazka A Paszczyński A. Lignin degradation: microorganisms, enzymes involved, genomes analysis and evolution. FEMS Microbiol Rev. 2017;41:941-62. https://doi.org/10.1093/femsre/fux049.

58. Wei YQ, Yang HJ, Luan Y, Long RJ, Wu YJ, Wang ZY. Isolation, identification and fibrolytic characteristics of rumen fungi grown with indigenous methanogen from yaks (Bos grunniens) grazing on the Qinghai-Tibetan Plateau. J Appl Microbiol. 2016;120:571-87.

59. Cheng YF, Jin W, Mao SY, Zhu W-Y. Production of citrate by anaerobic fungi in the presence of co-culture Methanogens as revealed by (1) H NMR ppectrometry. Asian-Australasian J Anim Sci. 2013;26:1416-23. https://doi.org/10.5713/ajas.2013.13134.

60. Van Soest PJ (editor). 11. Carbohydrates. In: Nutritional ecology of the ruminant. 2nd edn. Ithaca, NY: Cornell University Press; 1994. p. 156-76. https://doi.org/10.7591/9781501732355-012.

61. Baldwin RL, Allison MJ. Rumen metabolism. J Anim Sci. 1983;57(Suppl 2):461-77.

62. Shen J, Zheng L, Chen X, Han X, Cao Y, Yao J. Metagenomic analyses of microbial and carbohydrate-active enzymes in the rumen of dairy goats fed different rumen degradable starch. Front Microbiol. 2020;11:1003

63. Stewart RD, Auffret MD, Warr A, Wiser AH, Press MO, Langford KW, et al. Assembly of 913 microbial genomes from metagenomic sequencing of the cow rumen. Nat Commun. 2018;9:870. https://doi.org/10.1038/ s41467-018-03317-6.

64. Russell JB, Wallace RJ. Energy-yielding and energy-consuming reactions. In: Hobson PN, Stewart CS (editors). The Rumen microbial ecosystem. Dordrecht: Springer; 1997. p. 246-82. https://doi.org/10.1007/ 978-94-009-1453-7_6.

65. Ungerfeld EM. Metabolic hydrogen flows in rumen fermentation: principles and possibilities of interventions. Front Microbiol. 2020;11:589.

66. Wallace RJ, Rooke JA, McKain N, Duthie CA, Hyslop JJ, Ross DW, et al. The rumen microbial metagenome associated with high methane production in cattle. BMC Genomics. 2015;16:1-14.

67. Cunha CS, Marcondes MI, Veloso CM, Mantovani HC, Luiz B, Pereira GR, et al. Compositional and structural dynamics of the ruminal microbiota in dairy heifers and its relationship to methane production. Sci Food Agric. 2018;99:210-8. https://doi.org/10.1002/jsfa.9162.

68. Danielsson R, Dicksved J, Sun L, Gonda H, Müller B, Schnürer A, et al. Methane production in dairy cows correlates with rumen methanogenic and bacterial community structure. Front Microbiol. 2017;8:226.

69. Cunha CS, Veloso CM, Marcondes MI, Mantovani HC, Tomich TR, Pereira $L G R$, et al. Assessing the impact of rumen microbial communities on methane emissions and production traits in Holstein cows in a tropical climate. Syst Appl Microbiol. 2017:40:492-9.

70. Ramayo-Caldas Y, Zingaretti L, Popova M, Estellé J, Bernard A, Pons N, et al. Identification of rumen microbial biomarkers linked to methane emission in Holstein dairy cows. J Anim Breed Genet. 2020;137:49-59.

71. Friedman N, Jami E, Mizrahi I. Compositional and functional dynamics of the bovine rumen methanogenic community across different developmental stages. Environ Microbiol. 2017;19:3365-73.

72. Poulsen M, Schwab C, Borg Jensen B, Engberg RM, Spang A, Canibe $\mathrm{N}$, et al. Methylotrophic methanogenic Thermoplasmata implicated in reduced methane emissions from bovine rumen. Nat Commun. 2013:4:1-9.

73. Chen H, Gan Q, Fan C. Methyl-coenzyme reductase and its post-translational modifications. Front Microbiol. 2020;11:2437. https://doi.org/10. 3389/fmicb.2020.578356.

74. Duin EC, Wagner T, Shima S, Prakash D, Cronin B, Yáñez-Ruiz DR, et al. Mode of action uncovered for the specific reduction of methane emissions from ruminants by the small molecule 3-nitrooxypropanol. Proc Natl Acad Sci. 2016;113:6172-7. https://doi.org/10.1073/pnas.16002 98113.

75. Denman SE, Fernandez GM, Shinkai T, Mitsumori M, McSweeney CS. Metagenomic analysis of the rumen microbial community following inhibition of methane formation by a halogenated methane analog. Front Microbiol. 2015;6:1087.

76. Martínez-Álvaro M, Auffret MD, Stewart RD, Dewhurst RJ, Duthie CA, Rooke JA, et al. Identification of complex rumen microbiome interaction within diverse functional niches as mechanisms affecting the variation of methane emissions in bovine. Front Microbiol. 2020;1 1:659.

77. Kamke J, Soni P, Li Y, Ganesh S, Kelly WJ, Leahy SC, et al. Gene and transcript abundances of bacterial type III secretion systems from the rumen microbiome are correlated with methane yield in sheep. BMC Res Notes. 2017;10:1-14.

78. Kamke J, Kittelmann S, Soni P, Li Y, Tavendale M, Ganesh S, et al. Rumen metagenome and metatranscriptome analyses of low methane yield sheep reveals a Sharpea-enriched microbiome characterised by lactic acid formation and utilisation. Microbiome. 2016;4:1-16.

79. Liu C, Li XH, Chen YX, Cheng ZH, Duan QH, Meng QH, et al. Agerelated response of rumen microbiota to mineral salt and effects of their interactions on enteric methane emissions in cattle. Microb Ecol. 2017;73:590-601. https://doi.org/10.1007/s00248-016-0888-4.

80. Lyons T, Bielak A, Doyle E, Kuhla B. Variations in methane yield and microbial community profiles in the rumen of dairy cows as they pass through stages of first lactation. J Dairy Sci. 2018;101:5102-14.

81. Aguilar-Marin SB, Betancur-Murillo CL, Isaza GA, Mesa H, Jovel J. Lower methane emissions were associated with higher abundance of ruminal Prevotella in a cohort of Colombian buffalos. BMC Microbiol. 2020. https:// doi.org/10.1186/s12866-020-02037-6.

82. Paul SS, Dey A, Baro D, Punia BS. Comparative community structure of archaea in rumen of buffaloes and cattle. I Sci Food Agric. 2017:97:3284-93. 
83. Difford GF, Plichta DR, Løvendahl P, Lassen J, Noel SJ, Højberg O, et al. Host genetics and the rumen microbiome jointly associate with methane emissions in dairy cows. PLoS Genet. 2018;14:e1007580.

84. Min BR, Castleberry L, Allen H, Parker D, Waldrip H, Brauer D, et al. Associative effects of wet distiller's grains plus solubles and tannin-rich peanut skin supplementation on in vitro rumen fermentation, greenhouse gas emissions, and microbial changes. J Anim Sci. 2019;97:4668-81. https://doi. org/10.1093/jas/skz317.

85. Wang $M$, Wang $R$, Xie TY, Janssen $P H$, Sun XZ, Beauchemin KA, et al. Shifts in rumen fermentation and microbiota are associated with dissolved ruminal hydrogen concentrations in lactating dairy cows fed different types of carbohydrates. J Nutr. 2016;146:1714-21. https://doi.org/10.3945/jn.116. 232462.

86. Wang M, Wang R, Zhang X, Ungerfeld EM, Long D, Mao H, et al. Molecular hydrogen generated by elemental magnesium supplementation alters rumen fermentation and microbiota in goats. Br J Nutr. 2017;118:401-10. https://doi.org/10.1017/S0007114517002161.

87. Latham EA, Anderson RC, Pinchak WE, Nisbet DJ. Insights on alterations to the umen ecosystem by nitrate and nitrocompounds. Front Microbiol. 2016;7:228. https://doi.org/10.3389/fmicb.2016.00228.

88. Van Zijderveld SM, Gerrits WJJ, Apajalahti JA, Newbold JR, Dijkstra J, Leng RA, et al. Nitrate and sulfate: effective alternative hydrogen sinks for mitigation of ruminal methane production in sheep. J Dairy Sci. 2010;93:5856-66.

89. Granja-Salcedo YT, Fernandes RMI, De Araujo RC, Kishi LT, Berchielli TT, De Resende FD, et al. Long-term encapsulated nitrate supplementation modulates rumen microbial diversity and rumen fermentation to reduce methane emission in grazing steers. Front Microbiol. 2019;10:614.

90. Shah AM, Ma J, Wang Z, Hu R, Wang X, Peng Q, et al. Production of hydrogen sulfide by fermentation in rumen and its impact on health and production of animals. Processes. 2020;8:1169.

91. Fonty G, Joblin K, Chavarot M, Roux R, Naylor G, Michallon F. Establishment and development of ruminal hydrogenotrophs in methanogen-free lambs. Appl Environ Microbiol. 2007;73:6391-403. https://doi.org/10.1128/ AEM.00181-07.

92. Chen L, Luo Y, Wang H, Liu S, Shen Y, Wang M. Effects of glucose and starch on lactate production by newly isolated Streptococcus bovis S1 from Saanen Goats. Appl Environ Microbiol. 2016;82:5982-9. https://doi.org/10. 1128/AEM.01994-16.

93. Zhang R, Liu J, Jiang L, Mao S. Effect of high-concentrate diets on microbial composition, function, and the VFAs formation process in the rumen of dairy cows. Anim Feed Sci Technol. 2020;269:114619. https://doi.org/10. 1016/j.anifeedsci.2020.114619.

94. Prabhu R, Altman E, Eiteman MA. Lactate and acrylate metabolism by Megasphaera elsdenii under batch and steady-state conditions. Appl Environ Microbiol. 2012;78:8564-70. https://doi.org/10.1128/AEM.02443-12.

95. Shabat SKB, Sasson G, Doron-Faigenboim A, DurmanT, Yaacoby S, Berg Miller $M E$, et al. Specific microbiome-dependent mechanisms underlie the energy harvest efficiency of ruminants. ISME J. 2016;10:2958-72. https:// doi.org/10.1038/ismej.2016.62.

96. Schulmand MD, Valentino D. Factors influencing rumen fermentation: effect of hydrogen on formation of propionate. J Dairy Sci. 1976;59:1444-51. https://doi.org/10.3168/jds.S0022-0302(76)84383-4.

97. Gilmour M, Flint HJ, Mitchell WJ. Multiple lactate dehydrogenase activities of the rumen bacterium Selenomonas ruminantium. Microbiology. 1994;140:2077-84. https://doi.org/10.1099/13500872-140-8-2077.

98. van Gylswyk NO. Succiniclasticum ruminis gen. nov., sp. nov., a ruminal bacterium converting succinate to propionate as the sole energy-yielding mechanism. Int J Syst Bacteriol. 1995;45:297-300. https://doi.org/10.1099/ 00207713-45-2-297.

99. Mamuad L, Kim SH, Jeong CD, Choi YJ, Jeon CO, Lee S-S. Effect of fumarate reducing bacteria on in vitro rumen fermentation, methane mitigation and microbial diversity. J Microbiol. 2014;52:120-8. https://doi.org/10. 1007/s12275-014-3518-1.

100. Kim S-H, Mamuad LL, Kim D-W, Kim S-K, Lee S-S. Fumarate reductase-producing Enterococci reduce methane production in rumen fermentation in vitro. J Microbiol Biotechnol. 2016;26:558-66. https://doi.org/10.4014/ jmb.1512.12008.

101. Chen J, Harstad OM, McAllister T, Dörsch P, Holo H. Propionic acid bacteria enhance ruminal feed degradation and reduce methane production in vitro. Acta Agric Scand A Anim Sci. 2020;69:169-75. https://doi.org/10. 1080/09064702.2020.1737215.
102. Guo G, Shen C, Liu Q, Zhang SL, Shao T, Wang C, et al. The effect of lactic acid bacteria inoculums on in vitro rumen fermentation, methane production, ruminal cellulolytic bacteria populations and cellulase activities of corn stover silage. J Integr Agric. 2020;19:838-47. https://doi.org/10.1016/ S2095-3119(19)62707-3.

103. Jeyanathan J, Martin C, Eugène M, Ferlay A, Popova M, Morgavi DP. Bacterial direct-fed microbials fail to reduce methane emissions in primiparous lactating dairy cows. J Anim Sci Biotechnol. 2019;10:41. https://doi.org/10. 1186/s40104-019-0342-9.

104. Doyle N, Mbandlwa P, Kelly WJ, Attwood G, LiY, Ross RP, et al. Use of lactic acid bacteria to reduce methane production in ruminants, a critical review. Front Microbiol. 2019;10:2207.

105. Wang K, Nan X, Chu K, Tong J, Yang L, Zheng S, et al. Shifts of hydrogen metabolism from methanogenesis to propionate production in response to replacement of forage fiber with non-forage fiber sources in diets in vitro. Front Microbiol. 2018. https://doi.org/10.3389/fmicb.2018.02764.

106. Ramos-Morales E, de la Fuente G, Duval S, Wehrli C, Bouillon M, Lahmann $M$, et al. Antiprotozoal effect of saponins in the rumen can be enhanced by chemical modifications in their structure. Front Microbiol. 2017;8:399. https://doi.org/10.3389/fmicb.2017.00399.

107. Ren H, Su X, Bai H, Yang Y, Wang H, Dan Z, et al. Specific enrichment of microbes and increased ruminal propionate production: the potential mechanism underlying the high energy efficiency of Holstein heifers fed steam-flaked corn. AMB Express. 2019;9:209. https://doi.org/10.1186/ s13568-019-0937-8.

108. Pope PB, Smith W, Denman SE, Tringe SG, Barry K, Hugenholtz P, et al. Isolation of Succinivibrionaceae implicated in low methane emissions from Tammar Wallabies. Science (80-). 2011;333:646-8. https://doi.org/10.1126/ science.1205760.

109. Kristensen NB, Danfær A, Agergaard N. Absorption and metabolism of shortchain fatty acids in ruminants. Arch für Tierernaehrung. 1998;51:165-75. https://doi.org/10.1080/17450399809381916.

110. Aschenbach JR, Kristensen NB, Donkin SS, Hammon HM, Penner GB. Gluconeogenesis in dairy cows: the secret of making sweet milk from sour dough. IUBMB Life. 2010;62:869-77.

111. Bedford A, Beckett L, Hardin K, Dias NW, Davis T, Mercadante VRG, et al. Propionate affects insulin signaling and progesterone profiles in dairy heifers. Sci Rep. 2018;8:17629. https://doi.org/10.1038/s41598-018-35977-1.

112. Yang C. Acetogen communities in the gut of herbivores and their potentia role in Syngas fermentation. Fermentation. 2018;4:40. https://doi.org/10. 3390/fermentation4020040.

113. Gagen EJ, Padmanabha J, Denman SE, McSweeney CS. Hydrogenotrophic culture enrichment reveals rumen Lachnospiraceae and Ruminococcaceae acetogens and hydrogen-responsive Bacteroidetes from pasture-fed cattle. FEMS Microbiol Lett. 2015;362:fnv104. https://doi.org/10.1093/femsle/ fnv104.

114. Ungerfeld EM. A theoretical comparison between two ruminal electron sinks. Front Microbiol. 2013;4:319.

115. Lopez S, McIntosh FM, Wallace RJ, Newbold CJ. Effect of adding acetogenic bacteria on methane production by mixed rumen microorganisms. Anim Feed Sci Technol. 1999;78:1-9. https://doi.org/10.1016/S0377-8401(98) 00273-9.

116. Kim S-H, Mamuad LL, Islam M, Lee S-S. Reductive acetogens isolated from ruminants and their effect on in vitro methane mitigation and milk performance in Holstein cows. J Anim Sci Technol. 2020;62:1-13. https://doi.org/ 10.5187/jast.2020.62.1.1.

\section{Publisher's Note}

Springer Nature remains neutral with regard to jurisdictional claims in published maps and institutional affiliations. 